\title{
in the Air
}

\author{
Chris LeBeau, RUSA President, 2017-2018 \\ Chris LeBeau (lebeauc@umkc.edu) is Assistant Teaching \\ Professor at the iSchool at the University of Missouri.
}

$\mathrm{t}$ is my turn to welcome all new and returning members to RUSA. As we open the door on the new year this September, we find some interesting changes on our doorstep. While change is no stranger to our profession, perhaps some of the appeal of RUSA is the comfort we find in an association that does not change too much. Members enjoy established traditions and supportive, collegial networks that span our working lives. But, RUSA is an organic organization, so change and adaptation are part of the natural evolution of things. This year will be a year of adjustment and new beginnings. It will require patience when, not if, we encounter bumps in the road. The challenge before us is to manage the change while endeavoring to create forward momentum.

First, we will be greeting a new executive director for the first time in eight years. The position remains a shared arrangement with ASCLA. With all luck, the new director will be in place by the time this article appears. Expect a transition period as we get to know each other. We are wholly indebted to the RUSA staff for maintaining operations on an even keel for half a year in the absence of an executive director. My sincere thanks go to Leighann Wood, Jennifer Cross, and Melissa Tracy. I hope to arrange an online meet and greet with the new executive director in the fall.

Next, as we move forward, RUSA will be governed by a board of directors and advised by a leadership council comprising the board, committee chairs, RUSQ editor, divisional liaisons, section and interest group chairs, and RUSA staff.

Our leadership will be studying the new ALA conference redesign and the adaptations RUSA will need to make to accommodate it. This redesign promises to affect the way we manage our portion of the Annual conference. ALA President Jim O'Neil is encouraging divisions to hold more online meetings to free up your conference time to attend sessions! I encourage this. Space will be at a premium as the conference footprint downsizes.

We have revenue challenges. With the help of RUSA office staff, we are scrutinizing our expenses and redirecting our efforts toward activities that bring maximum member value and additional revenue. We need to devise new, less expensive ways to manage some of our programs like achievement recognition. We are aggressively seeking outside funding primarily through the efforts of Celia Ross who serves as RUSA's vendor relations coordinator. Section members also are actively soliciting vendor support. We will consider 
new fundraising efforts. We must scale our programs and activities to a level that staff, volunteers and funding levels can reasonably support.

If this is not change enough, the board spent the year voting on division restructuring proposals developed by the Organization and Planning Committee under the tireless leadership of Beth German. Kudos to the entire committee (listed below) for earnestly tackling this whale of a job. The committee was composed of long-standing RUSA members, deeply involved in the association. They formed their ideas from data, past surveys, and their own observations and knowledge of the functioning of the association. We restructure not for the sake of change, but to follow best practices for nonprofit organizations and to respond to changing conditions within our organization and within RUSA's internal office. The Organization and Planning Committee will become an Implementation Task Force that will guide the organization through the change process. You can read more about the structural changes in Alesia McManus's message to membership in RUSA Quarterly Update (May 23, 2017) (www.rusaupdate.org/quar terly_update/from-the-president-sul7).

What are the benefits of these structural changes?

- Swifter board action resulting from a stepped up meeting schedule of monthly meetings.

- While the board will retain a large profile in the short term, it will shrink in the long term, thereby right- sizing the governance to be in keeping with today's nonprofit models.

- Quorum requirements will be met more easily with some smaller committees enabling them to complete their work more expediently.

- RUSA staff bring us new talent and capabilities. Some things our volunteers try to maintain may be done more efficiently by our dedicated internal staff.

- Our Membership Committee will become Member Engagement. In addition to the traditional committee duties, this committee will add an emphasis on recruiting new members and engaging members new to the profession. It is predictable that RUSA will experience a rise in retirements, so it is important we attract the next generation.

RUSA has had a tremendously busy year under the energetic leadership of Alesia McManus. (Between the two of us, I think I tested the limits of my university email system.) Several task forces have presented us with reports with many good suggestions through which we continue to work.

Looking past the structural changes, I am excited about several things we are working on and some things we can develop:

- New course offerings from our Professional Development Committee

- Conversation series with leaders in the field

- Conversations about the future directions of reference

- Lightning polls on topics of your choice-do you have burning questions for which you would like quick responses

- Members' contributions on our new RUSA Update platform; share your studies, white papers, professional observations, innovations, member news, and opinions

- Contributions from our younger members from whom we can learn so much

- Continued public, academic, and special library collaborations

- The shift of RUSQ to full open access, increasing its visibility and access in the library community

I welcome the opportunity to serve the membership this coming year. I have many good friends and colleagues among you. I want to hear your ideas and suggestions for making RUSA a more vibrant association, and an association of choice. I look forward to working with all the RUSA leadership and with our newly elected RUSA leaders. Ann Brown, RUSA's new vice-president, brings a depth of knowledge of the association that should prove to be a great resource in this time of change. I want to express my thanks to the executive committee (Alesia McManus, Anne Houston, Sarah Hammill, and Kate Oberg) for their guidance this past year. RUSA officers and staff devote a tremendous amount of time and energy to our organization and to ALA, and we all thank them for their dedication.

The Organization and Planning Committee is Beth German, Tina Baich, Ann Brown, Anne Houston, Erin Rushton, Arlene McFarlin Weismantel, Bobray Bordelon Jr., Donna Brearcliffe, Jennifer Jacobs, Jenny Presnell, Colleen Seale, Matthew Wayman, and Chris LeBeau. Alesia McManus was highly involved. 